\title{
The NO level in young patients with arterial hypertension and metabolic disorders
}

\author{
Nedezhda Lyamina*, VN Senchihin and Svetlana Lyamina
}

\author{
Address: Saratov Research Institute for Cardiology, Saratov, Russia \\ Email: Nedezhda Lyamina* - liana@san.ru \\ * Corresponding author
}

\author{
from 2nd International Conference of cGMP Generators, Effectors and Therapeutic Implications \\ Potsdam, Germany, 10-12 June, 2005 \\ Published: 16 June 2005 \\ BMC Pharmacology 2005, 5(SuppI I):P33 doi:I0.II86/I47I-22 I0-5-SI-P33
}

The aim of the research work was to study the NO level in patients with the I and II degree of arterial hypertension $(\mathrm{AH})$ and metabolic disorders.

The general research group consists of 75 patients: I group -20 patients with normal levels of blood pressure (32.5 \pm 3.8 years $)$, II group - 27 patients with AH I $(34.6 \pm 4.6$ years), III group - 28 patients with AH II $(36.2 \pm 3.7$ years), with the duration of hypertension from 1 to 10 years.

The NO level was determined by the summary concentration of stable NO metabolites - nitrates and nitrits $\left(\mathrm{CM}_{\mathrm{NO}}\right)$ in plasma (Moshage,1995, WPI Nitralyzer-II, USA). The lipid spectrum, level of glucose on an empty stomach and tolerance to glucose were studied, anthropometric research was carried out with the definition of mass index and the degree of obesity. The daily monitoring of blood pressure was carried out on the TM-2421 AND monitor. The analysis of the resieved data showed that in the II group of patients the level of $\mathrm{CM}_{\mathrm{NO}}$ was $40.3 \%$ lower, and in the III group of patients it was $96.3 \%$ lower, then in the I group patients.

With the increasing of metabolic disorders degree (the combination of dyslipidemia, obesity and breach tolerance to glucose) the level of $\mathrm{CM}_{\mathrm{NO}}$ decreses and the level of blood pressure increases, so the metabolic disorders degree corresponds the more expressed decrease of $\mathrm{NO}$ production and increase of hypertension degree, which show the pathogenetic community of metabolic disorders and arterial hypertension. The decrease of NO production showed the dependence with blood pressure level, which increases with the duration of arterial hypertention.
So, metabolism of vasoactive substance NO in young patients with arterial hypertension depends on the degree and length of arterial hypertension and the degree of metabolic disorders. 